\title{
Hormonal Responses to Psychological Stress and Family History of Alcoholism
}

\author{
Magdalena Uhart', Lynn Oswald ${ }^{2,3}$, Mary E McCaul ${ }^{2}$, Rachel Chong' and Gary S Wand*,1,2 \\ 'Department of Medicine, The Johns Hopkins University School of Medicine, Baltimore, MD, USA; '2 Department of Psychiatry, The Johns Hopkins \\ University School of Medicine, Baltimore, MD, USA; ${ }^{3}$ Department of Family and Community Health, University of Maryland School of Nursing, \\ Baltimore, MD, USA
}

\begin{abstract}
The present study was designed to determine whether stress hormones and subjective responses to a psychological stressor were different in nonalcoholic offspring from families with a history of alcohol dependence (family history positive, FHP) than in nonalcoholic offspring without a family history of alcohol dependence (family history negative, FHN). Forty-five healthy subjects ( 17 FHP, 28 FHN), between the ages of 18 and 29 years, completed the Trier Social Stress Test (TSST). The TSST consisted of 5 min of public speaking followed by 5 min of mental arithmetic. Three baseline and five post-TSST blood samples were drawn. Pre- and post-TSST self-report measures of anxiety were obtained. Cortisol, adrenocorticotropin (ACTH), and prolactin significantly increased in response to the TSST in the entire study sample $\left(F_{(1,187)}=70.22, p<0.001, F_{(I, 143)}=33, p<0.001\right.$, and $F_{(I, 134)}=14.37$, $p<0.001$, respectively). Cortisol responses were influenced by an interaction between racial composition and family history of alcoholism $\left(F_{(1,57)}=4.50, p=0.038\right)$. Among Caucasian subjects, FHP subjects had greater cortisol response to the TSST compared to $F H N$ subjects $\left(F_{(1,57)}=4.45\right.$, $p=0.039)$. No family history effect was identified in African-American subjects. Adrenocorticotropin responses did not differ between FHP and FHN subjects. Adrenocorticotropin response was positively associated with baseline ACTH levels in FHN subjects ( $t=5.02$, $p=<0.00 \mathrm{I}$ ), but not in FHP subjects. Prolactin responses did not differ between FHP and FHN subjects. Anxiety response scores (postTSST scores minus pre-TSST scores) were higher in FHP subjects compared with FHN subjects $(z=-2.67, p=0.007)$. In addition, anxiety response scores were positively associated with cortisol response levels to the TSST in FHN subjects $(t=4.52, p<0.00 \mathrm{I})$. In contrast, anxiety responses were negatively associated with cortisol responses in FHP subjects $(t=-2.30, p=0.024)$. Our findings are consistent with theories that greater reactivity to stress is associated with greater risks for alcoholism. Furthermore, the findings suggest that the association between the hypothalamic-pituitary-adrenal axis hormonal response and the subjective perception of stress might be deranged in offspring of alcoholics.
\end{abstract}

Neuropsychopharmacology (2006) 3 I, 2255-2263. doi: I 0. I 038/sj.npp. I 30 I063; published online 22 March 2006

Keywords: alcoholism; family history; cortisol; adrenocorticotropin (ACTH); prolactin; Trier Social Stress Test

\section{INTRODUCTION}

Stress can be defined as any disruption of homeostasis (Miller and O'Callaghan, 2002). Following the disturbance of homeostasis, activation of the hypothalamic-pituitaryadrenal (HPA) axis is an essential adaptive mechanism that allows the body to maintain physiological stability. Corticotrophin-releasing hormone (CRH) stimulates the synthesis and release of adrenocorticotropin (ACTH) by the anterior pituitary, which in turn stimulates the synthesis and release of cortisol by the adrenal cortex. Individual variation in the

\footnotetext{
*Correspondence: Dr GS Wand, Department of Medicine, The Johns Hopkins University School of Medicine, Ross Research Building, Room 863, 720 Rutland Avenue, Baltimore, MD 21205, USA, Tel: + I 410 955 7225, Fax: + I 410955 084I, E-mail: gwand@jhmi.edu Received II August 2005; revised 9 February 2006; accepted 10 February 2006

Online publication: 16 February 2006 at http://www.acnp.org/citations/ Npp02 I 606050503/default.pdf
}

stress response and, thereby, the vulnerability to associated illnesses are influenced by both environmental and genetic factors. In fact, there is evidence that heritable influences account for approximately $32-98 \%$ of the variance in the glucocorticoid response to psychological stress (Federenko et al, 2004).

Both enhanced and attenuated hormonal responses to stress are maladaptive. Chronic HPA axis dysregulation is associated with the development of mood and anxiety disorders, such as depression (Sapolsky, 2000; Gold and Chrousos, 2002; Sherwood Brown et al, 2004). Moreover, excess cortisol exposure is related to a variety of medical conditions including hypertension, atherosclerosis, obesity, insulin resistance, dyslipidemia, bone demineralization, and impaired immunity (McEwen, 1998; Tsigos and Chrousos, 2002). Likewise, stress contributes to the development and maintenance of substance use disorders, such as alcohol dependence (Brown et al, 1990; Cole et al, 1990; Brewer et al, 1998; Jose et al, 2000; Sussman and Dent, 2000; 
Karlsgodt et al, 2003; King et al, 2003; Dawson et al, 2005). For instance, studies of nonhuman primates under different early rearing conditions have shown that enhanced HPAaxis hormonal activation during stress is positively correlated with alcohol consumption (Higley et al, 1991; Fahlke et al, 2000). Although the processes underlying this relationship remain inconclusive, there is evidence in preclinical models that glucocorticoids influence alcohol consumption by enhancing mesolimbic dopamine accumulation (Marinelli and Piazza, 2002). In addition, glucocorticoids increase the expression of $\mathrm{CRH}$ in the amygdala (Cook, 2002; Robison et al, 2004), which plays a crucial role in anxiety behaviors and in promoting alcohol intake (McBride, 2002; Koob, 2003; Pandey, 2003).

A positive family history for alcoholism is recognized as a major risk factor for the development of alcohol dependence (Cotton, 1979; Goodwin, 1984). Furthermore, genetic factors account for a large proportion of the increased risk in children of alcohol-dependent parents (Goodwin et al, 1974; Cloninger et al, 1981; Heath et al, 1997; Prescott and Kendler, 1999). In order to uncover markers that might identify those at increased risk for alcohol dependence, nonalcoholic offspring of alcohol-dependent persons have been investigated (Begleiter et al, 1984; Schuckit et al, 1987; Wand et al, 1994). The family history of alcoholism research strategy compares nonalcoholic offspring from families with a high density of alcoholism (family history positive, FHP) with those from families with no history of alcoholism (family history negative, FHN). Using this research design, HPA axis responses following an ethanol challenge have been shown to predict future development of alcoholism (Schuckit and Smith, 1996). Furthermore, differences in HPA-axis dynamics as a function of family history of alcoholism have been found by stimulating the HPA axis with the opioid receptor antagonist naloxone (Wand et al, 1998, 1999a, b, 2001; Hernandez-Avila et al, 2002) and CRH (Waltman et al, 1994). More recently, hormonal responses to activation of the HPA axis by psychological stressors have been reported to differ in subjects at high and low risk of alcoholism (Dai et al, 2002; Zimmermann et al, 2004). However, results have been contradictory and the nature of these associations remains inconclusive. Further investigation is needed to determine whether HPA-axis responses to stressful events are associated with vulnerability for alcoholism.

The aim of the present study was to determine whether there are differences in the hormonal and anxiety responses to a psychological stressor between nonalcoholic offspring from families with alcohol-dependent individuals and nonalcoholic subjects without a family history of alcohol dependence.

\section{METHODS}

\section{Subjects}

Forty-five healthy subjects between the ages of 18 and 29 years were recruited for participation by newspaper advertisements and posted flyers in the Baltimore area. Subjects who appeared to qualify for research participation based on a telephone screen were invited to the laboratory for an interview. All participants provided written informed consent for the protocol approved by the Johns Hopkins Medicine Institutional Review Board. Subject assessment included a medical history and physical exam performed by a physician, complete blood count, comprehensive metabolic panel (including renal and hepatic function tests), electrocardiogram, urinalysis, alcohol breathalyzer test, and urine toxicology screen. Assessment of race of participants was by self-report. The Semi-Structured Assessment for the Genetics of Alcoholism (SSAGA) (Bucholz et al, 1994) was administered by a master's degree-level interviewer to identify DSM-IV axis I psychiatric diagnoses, including past or current diagnoses of alcohol and drug abuse or dependence. Subjects determined to be free of such diagnoses were administered the Family History Assessment Module (FHAM) (Rice et al, 1995). This module determines the number of first-, second-, and third-degree paternal and maternal relatives who have demonstrated symptoms of selected psychiatric disorders and alcohol or drug abuse or dependence. Subjects designated as FHP had a history of alcoholism in either father or mother only, or father or mother as well as one or more first- or seconddegree relatives (Table 1). Subjects were categorized as FHN if no first or second degree relative was reported to be alcohol dependent. Based on these criteria, 17 subjects were designated as FHP and 28 subjects were designated as FHN.

Exclusion criteria were as follows: (a) presence of medical conditions, (b) current or lifetime history of a DSM-IV axis I disorder, including alcohol/drug abuse or dependence, (c) use of any psychoactive medications within the past 30 days, (d) treatment in the last 6 months with any medication that may affect opioid or HPA-axis function, including antidepressants, neuroleptics, sedative hypnotics, glucocorticoids, appetite suppressants, estrogens, opiates, or dopamine medications, (f) consumption of more than 30 alcoholic drinks/month, or (g) positive urine toxicology screen. Women using a hormonal method of birth control were excluded. All female subjects completed the TSST during the follicular phase of their menstrual cycle determined by menstrual diary and progesterone levels.

\section{Behavioral Measures}

Baseline behavioral measures were administered during the initial assessment interview to establish if there were group differences in anxiety, mood, or personality dimensions at baseline as a function of family history of alcoholism. The assessments included the State-Trait Anxiety Inventory (STAI) (Spielberger, 1983), Beck Depression Inventory, 2nd Edition (BDI-II) (Beck et al, 1996), Perceived Stress Scale (PSS) (Cohen et al, 1983), Life Experiences Survey (LES) (Sarason et al, 1978), Revised NEO Personality Inventory (NEO-PI-R) (Costa and McCrae, 1992a,b), Hassles and Uplifts Scales (H-U) (Lazarus and Folkman, 1989), and the Brief Symptom Inventory (BSI) (Derogatis and Melisaratos, 1983).

State-trait anxiety inventory. This 40 -item self-rating scale measures state anxiety (temporal anxiety based on situational state) and trait anxiety (general anxiety levels or proneness to anxiety). The state scale consists of 20 statements evaluating how respondents feel 'right now'. The trait scale consists of 20 statements that assess how 
Table I Demographic Characteristics by Family History of Alcoholism

\begin{tabular}{|c|c|c|}
\hline & \multicolumn{2}{|c|}{$\begin{array}{l}\text { Trier Social Stress Test } \\
\qquad n=45\end{array}$} \\
\hline & $\begin{array}{l}\text { Family history } \\
\text { positive }\end{array}$ & $\begin{array}{c}\text { Family history } \\
\text { negative }\end{array}$ \\
\hline Sample size & 17 & 28 \\
\hline Age, mean (SD) (years) & $21.5(2.8)$ & $21.7(2.8)$ \\
\hline \multicolumn{3}{|l|}{ Gender, no. (\%) } \\
\hline Male & $10(58.8)$ & $20(7 \mid .4)$ \\
\hline Female & $7(4 \mid .2)$ & $8(28.6)$ \\
\hline \multicolumn{3}{|l|}{ Race, no. (\%) } \\
\hline Caucasian & $12(70.6)$ & $22(78.6)$ \\
\hline African American & $5(29.4)$ & $6(21.4)$ \\
\hline $\mathrm{BMI}$, mean (SD) $\left(\mathrm{kg} / \mathrm{m}^{2}\right)^{\mathrm{a}}$ & $25.5(3.1)$ & $23.6(2.2)$ \\
\hline Education, mean (SD) (years) & | $4.4(1.7)$ & | $4.6(1.8)$ \\
\hline Drinking episodes per week, mean (SD) & I.0 (0.9) & $0.7(0.8)$ \\
\hline Drinks per drinking episode, mean (SD) & $3.7(2.2)$ & $2.6(2.5)$ \\
\hline \multicolumn{3}{|c|}{ Family history members with a diagnosis of alcohol dependence } \\
\hline Father only, no. (\%) & $3(17.6)$ & \\
\hline Father+second degree, no. $(\%)^{\mathrm{b}}$ & $12(70.6)$ & \\
\hline Mother only, no. (\%) & । (5.9) & \\
\hline Mother+first and second degree, no. (\%) & । (5.9) & \\
\hline
\end{tabular}

${ }^{\mathrm{a} G r o u p ~ d i f f e r e n c e s ~} p<0.05$.

${ }^{b}$ One subject had, in addition, a first-degree relative with alcohol dependence diagnosis.

respondents generally feel. Scores for both the state and trait anxiety scales can vary from a minimum of 20 to a maximum of 80 .

\section{General Procedure}

Following the initial assessment interview, subjects reported to the Johns Hopkins Hospital Outpatient General Clinical Research Center (GCRC) to complete a modified version of the TSST (Kirschbaum et al, 1993). Subjects were instructed to obtain adequate sleep the night before the challenge and to report any stressful situations that may have occurred during the previous week. They were also instructed to refrain from any alcohol, illicit drugs, or over-the-counter medications for $48 \mathrm{~h}$ before participating in the study protocol. Urine toxicology screens were completed before the session (Phamatech Inc., San Diego, CA). On the day of the challenge, subjects fasted from 1000 hours until testing was completed.

\section{Trier Social Stress Test}

The TSST consists of $5 \mathrm{~min}$ of public speaking, followed by 5 min of a mental arithmetic task and was completed as previously described in detail (Uhart et al, 2004). Upon arrival at the GCRC, an intravenous catheter was inserted into a forearm vein at 1200 hours. Baseline blood samples for ACTH, cortisol, and prolactin were obtained at 1300, 1315, and 1330 hours. Subjects then participated in the TSST. Immediately following completion of the TSST, five additional blood specimens for ACTH, cortisol, and prolactin were obtained at $15 \mathrm{~min}$ intervals. The state anxiety scale of the STAI was repeated on the day of the TSST; it was administered before the psychological stressor at 1245 hours and immediately following the TSST, at 1355 hours.

\section{Hormone Assays}

Hormones were assayed as previously described (Blevins et al, 1994). Plasma concentrations of ACTH were assayed by a two-site IRMA (Nichols immunoradiometric assay). Intra-assay and inter-assay coefficients of variance were each less than $9 \%$, and the detection limit of the assay was $1 \mathrm{pg} / \mathrm{ml}$. Plasma concentrations of cortisol were measured by radioimmunoassay (Diagnostic Products Corporation Inc., Los Angeles, CA). Intra-assay and inter-assay coefficients of variation were 6 and $8.5 \%$, respectively. The detection limit for the assay was $0.2 \mu \mathrm{g} / \mathrm{dl}$. Plasma concentrations of prolactin were measured by radioimmunoassay (Incstar Inc., San Francisco, CA). Intra-assay and interassay coefficients of variance were each less than $9 \%$, and the detection limit for the assay was $0.1 \mathrm{ng} / \mathrm{ml}$.

\section{Statistical Analysis}

Group differences in demographic characteristics, mood, personality scores, and baseline hormone levels (ie, ACTH, cortisol, and prolactin) were evaluated as a function of family history of alcoholism with $t$-tests for continuous variables and $\chi^{2}$ analyses for categorical variables. The primary outcome measures were plasma hormone levels during the TSST. Hormonal values were transformed to the logarithmic scale before analysis when non-normality was established. The mean baseline for each hormone was calculated by taking the average of the three pre-TSST measurements. Longitudinal data analytic methods were used to examine hormonal responses to the TSST, taking into account intraperson correlations among the repeated measurements over time. Based on examination of the data, we assumed that the structure of the correlation within subjects was autoregressive. Separate models were conducted for each of the three hormones. The models included the fixed effects of family history of alcoholism, gender, and race as class variables, time and time ${ }^{2}$ to adjust for nonlinear time trends, and baseline hormone levels as continuous covariates; subjects were included as a random effect. Two-way interaction terms were included in the initial models, but were not maintained if their estimates were not statistically significant. Post hoc tests of simple effects were conducted to evaluate interactions between categorical variables; separate slopes models were used to examine interactions between family history of alcoholism and continuous covariates. Although BMI differed by family history, BMI was not included as a covariate in the longitudinal models owing to the restricted range of scores and the lack of relationship with hormone levels in simple correlations. 
To further verify these findings, we conducted a second set of analyses in which hormonal values were summarized as area under the time response curve (AUC), calculated by trapezoidal approximation from the last sample obtained before the speech to the end of the session. A measure of AUC response was calculated by subtracting the rectangle defined by the mean baseline hormonal value multiplied by the time interval between all measurements during the challenge (Pruessner et al, 2003). A regression analysis was conducted using hormonal AUC response as the dependent measure, family history of alcoholism as the covariate of interest, and gender and race as additional covariables. Two-way interaction terms were included in the initial models, but were not maintained if their estimates were not statistically significant.

Secondary analyses included examination of the subjective anxiety responses during the session. First, to test if the TSST significantly raised anxiety scores, differences between pre- and post-TSST anxiety scores were examined in each FH group. Owing to non-normality of the anxiety scores, this analysis was carried out with Wilcoxon signedrank tests. Second, group differences in anxiety scores before the TSST, following the TSST and anxiety responses were examined with Wilcoxon rank-sum tests. Anxiety responses were calculated for each subject by subtracting anxiety scores (STAI) before the TSST from anxiety scores following the TSST. Anxiety scores were adjusted for gender and race for the analysis. Third, we examined the relationship between cortisol responses to the TSST and anxiety responses during the session. Cortisol levels were used as the dependent measure in longitudinal mixed models that included fixed effects for gender, race, and family history as class variables; time and time ${ }^{2}$ to adjust for nonlinear time trends, and baseline hormone levels and anxiety responses as continuous covariables; subjects were included as a random effect. Interaction terms were examined, but not maintained in the models if their estimates were not statistically significant. Post hoc tests were conducted as described in the previous paragraph.

To further verify these findings and graphically depict relationships between cortisol and anxiety responses to the TSST in each of the family history groups, cortisol data were summarized as AUC calculated as previously described. A regression analysis was conducted in each group using cortisol AUC response as the dependent measure, anxiety response as the independent variable, and gender and race as additional covariables. Figures shown in the manuscript were constructed from the adjusted values. All analyses were two-sided with a significance level of $p<0.05$ and were conducted with SAS, version 9.1. For the longitudinal analysis, the degrees of freedom were calculated by Kenward-Roger method and are rounded in the results section.

\section{RESULTS}

\section{Demographics}

Demographic characteristics are presented in Table 1. Subjects averaged 21 years of age, completed on average 2 years of college, and were predominantly Caucasian. Typically, subjects drank 1 day/week, averaging 3 drinks/ episode. There were no statistically significant differences between the two groups in terms of age, gender, racial composition, educational status, or drinking history. Although the groups differed in BMI $(t=-2.41$, $p=0.020$ ), BMI was not included as a covariate in the models owing to the restricted range of scores and the lack of relationship with hormone levels in simple correlations. There was only one subject who was a smoker of 3 cigarettes/day in the FHN group.

\section{Behavioral Instruments at Baseline}

Behavioral measures completed during the initial assessment interview are presented in Table 2. There were no statistically significant differences between the FHP and FHN groups in STAI trait and state anxiety scores, depression scores (BDI-II), perceived stress (PSS), number and severity of negative life events (LES), NEO PI-R domain scores, or in Hassles frequency and severity scores (H-U). Compared to FHN subjects, FHP subjects scored higher on the obsessive-compulsive dimension of the BSI (mean $(\mathrm{SD})=0.60(0.51)$ vs $0.31(0.40), t=-2.14, p=0.038)$ but did not differ in other BSI dimensions or in BSI global severity index.

\section{Adrenocorticotropin (ACTH)}

There were no mean baseline differences in plasma ACTH concentrations by family history group. There was a

Table 2 Behavioral Measurements at Baseline by Family History of Alcoholism

Trier Social Stress Test $n=45$

$\begin{array}{cc}\begin{array}{c}\text { Family history } \\ \text { positive }\end{array} & \begin{array}{c}\text { Family history } \\ \text { negative }\end{array}\end{array}$

\begin{tabular}{lll}
\hline Sample size & 17 & 28
\end{tabular}

$\begin{array}{lcc}\text { STAI } & & \\ \quad \text { Trait anxiety, mean (SD) } & 30.9(9.9) & 27.9(7.6) \\ \quad \text { State anxiety, mean (SD) } & 31.1(7.9) & 27.5(8.7) \\ & & \\ \text { Depression (BDI-II), mean (SD) } & 3.2(4.3) & 2.4(3.1) \\ \begin{array}{l}\text { Perceived Stress Scale (PSS), mean (SD) } \\ \text { No. of negative events/severity (LES), }\end{array} & \text { I } 0.8(5.2) & 9.8(5.7) \\ \text { mean (SD) } & & \end{array}$

NEO-PI-R

$\begin{array}{lll}\text { Neuroticism factor, mean (SD) } & 44.6(9.7) & 42.0(8.0) \\ \text { Extraversion factor, mean (SD) } & 52.4(8.5) & 51.2(8.7) \\ \text { Openness factor, mean (SD) } & 55.4(10.8) & 54.8(12.5) \\ \text { Agreeableness factor, mean (SD) } & 48.8(10.8) & 50.0(9.8) \\ \text { Conscientiousness factor, mean (SD) } & 51.8(12.6) & 55.6(9.6)\end{array}$

Hassles frequency/severity (H-U), mean I7.2 (5.2)/I.3 (0.3) I5.6 (9.4)/।.3 (0.5) (SD)

Global severity index (BSI), mean (SD) $0.2(0.2) \quad 0.1(0.2)$ 
significant increase in ACTH response to the TSST in the entire study sample $\left(\mathrm{F}_{(1,143)}=33, p<0.001\right)$. Adrenocorticotropin significantly increased in response to the TSST in the Caucasian and African-American subgroups $\left(\mathrm{F}_{(1,106)}=\right.$ 28.01, $p<0.001$, and $\mathrm{F}_{(1,39)}=5.64, p=0.022$, respectively). Findings from longitudinal analysis showed that there were no differences in ACTH response as a function of family history of alcoholism. A significant interaction on ACTH TSST response was found between family history of alcoholism and baseline levels of ACTH $\left(\mathrm{F}_{(1,43)}=5.48\right.$, $p=0.023$ ). Adrenocorticotropin responses were positively associated with baseline ACTH levels in FHN subjects $(t=5.02, p=<0.001)$, but were not associated with baseline ACTH levels in FHP subjects (Figure 1). Findings from AUC analysis again showed there were no differences in ACTH response as a function of family history of alcoholism.

\section{Cortisol}

There were no mean baseline differences in plasma cortisol concentrations by family history group. There was a significant increase in cortisol response to the TSST in the entire study sample $\left(\mathrm{F}_{(1,187)}=70.22, p<0.001\right)$. Cortisol significantly increased in response to the TSST in the Caucasian and African-American subgroups $\left(\mathrm{F}_{(1,141)}=\right.$ $71.51, p<0.001$, and $\mathrm{F}_{(1,47)}=5.43, p=0.024$, respectively). Baseline cortisol levels were positively associated with cortisol response to the TSST in the entire study sample $\left(\mathrm{F}_{(1,57)}=35.64, p=<0.001\right)$. Findings from longitudinal analyses showed an interaction between race and family history of alcoholism $\left(\mathrm{F}_{(1,57)}=4.50, p=0.038\right)$. Among Caucasian subjects, FHP subjects had greater cortisol response to the TSST compared to FHN subjects $\left(\mathrm{F}_{(1,57)}=\right.$ $4.45, p=0.039)$. No family history effect was identified in African-American subjects (Figure 2). Similarly, the relationship between cortisol response and family history was analyzed using AUC, and the interaction between race and family history of alcoholism was marginally significant $(t=-1.80, p=0.08)$.

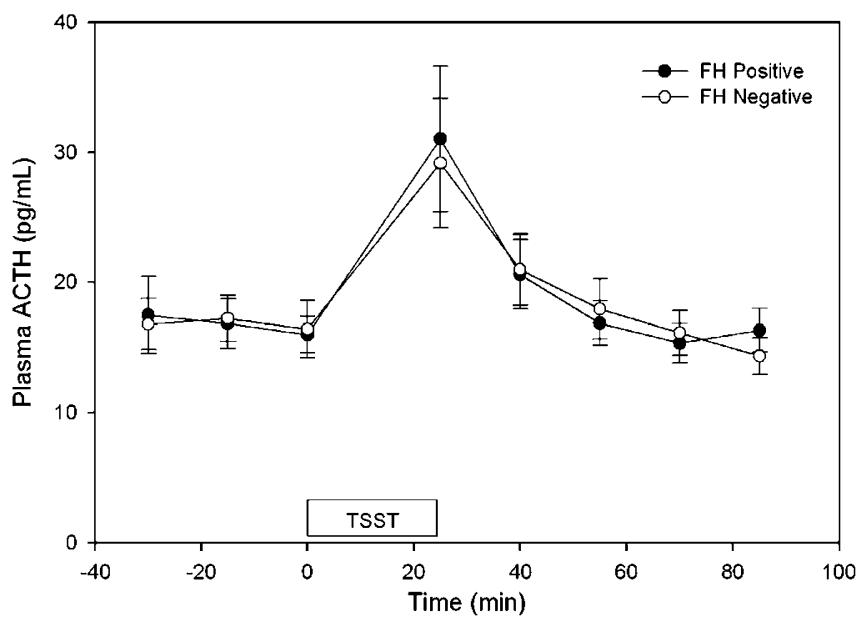

Figure I Plasma adrenocorticotropin response to TSST by family history of alcoholism. Values reflect means (SE). TSST box denotes TSST, which includes $5 \mathrm{~min}$ of instructions period, $10 \mathrm{~min}$ of preparation period, and 10 min of public speaking and mental arithmetic task. Number of subjects in each subgroup: $\mathrm{FHP}=17, \mathrm{FHN}=28$.

\section{Prolactin}

There were no mean baseline differences in plasma prolactin concentrations by family history group. There was a significant increase in prolactin response to the TSST in the entire study sample $\left(\mathrm{F}_{(1,134)}=14.37, p<0.001\right)$. Prolactin significantly increased in response to the TSST in the Caucasian subgroup $\left(\mathrm{F}_{(1,103)}=15.56, p<0.001\right)$. However, prolactin increase in response to the TSST was not significant in the African-American subgroup. Baseline prolactin levels were positively associated with prolactin response to the TSST in the entire study sample $\left(\mathrm{F}_{(1,42)}=148.55, p=<0.001\right)$. Findings from longitudinal analysis showed that there were no differences in prolactin response as a function of family history of alcoholism (Figure 3). Similarly, findings from AUC analysis again showed that there were no differences in prolactin response as a function of family history of alcoholism.

\section{Anxiety State Scale before the TSST and Following the TSST}

Comparison of pre- and post-TSST state anxiety scores indicated that the TSST significantly raised anxiety in both FHP and FHN subjects $(z=-2.89, p=0.003$ and $z=-3.16$, $p=0.001$, respectively). Family history groups did not differ in anxiety scores before the TSST or immediately following the TSST. However, anxiety response scores (post-TSST scores minus pre-TSST scores) were significantly higher in FHP individuals compared with FHN individuals $(z=-2.67$, $p=0.007$ ) (Table 3). Furthermore, we found that the relationship between cortisol and anxiety responses to the TSST differed on the basis of family history of alcoholism. A significant interaction was observed between anxiety response and family history of alcoholism in the longitudinal analyses $\left(\mathrm{F}_{(1,57)}=19.23, p<0.001\right)$. Findings of post hoc analyses further showed that cortisol responses to the TSST were positively associated with anxiety responses in FHN subjects $(t=4.52, p<0.001)$; conversely, cortisol responses

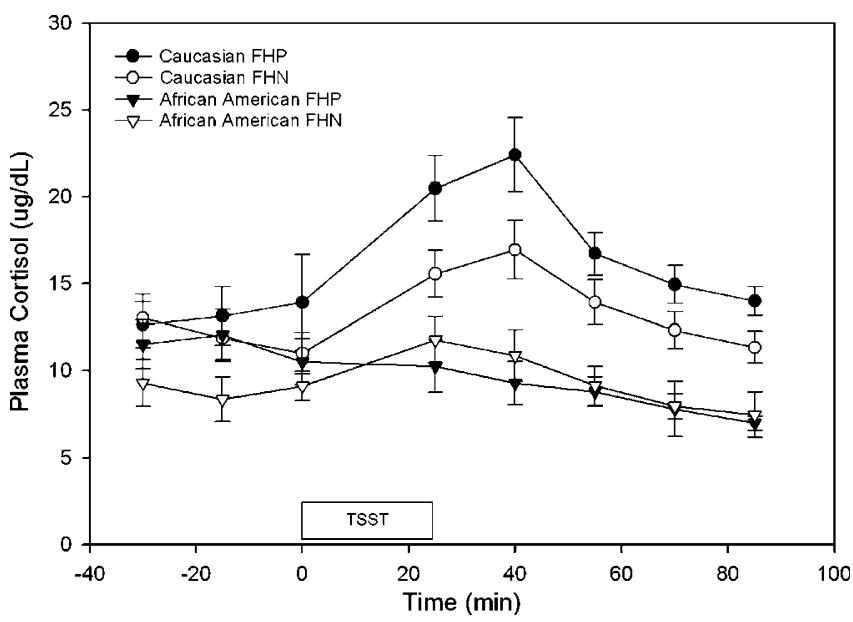

Figure 2 Plasma cortisol response to TSST by family history of alcoholism. Values reflect means (SE). TSST box denotes TSST, which includes $5 \mathrm{~min}$ of instructions period, $10 \mathrm{~min}$ of preparation period, and 10 min of public speaking and mental arithmetic task. Number of subjects in each subgroup: Caucasian $\mathrm{FHP}=12$, Caucasian $\mathrm{FHN}=22$, African American $\mathrm{FHP}=5$, African American $\mathrm{FHN}=6$. 


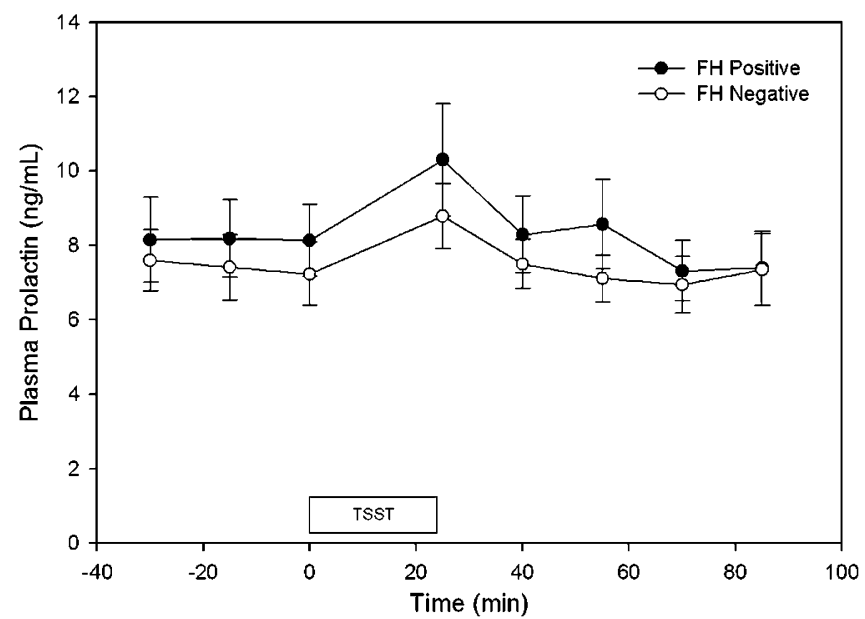

Figure 3 Plasma prolactin response to TSST by family history of alcoholism. Values reflect means (SE). TSST box denotes TSST, which includes $5 \mathrm{~min}$ of instructions period, $10 \mathrm{~min}$ of preparation period, and 10 min of public speaking and mental arithmetic task. Number of subjects in each subgroup: $\mathrm{FHP}=17, \mathrm{FHN}=28$.

Table 3 Anxiety State Scale (STAI) Scores by Family History of Alcoholism, Adjusted for Gender and Race

\begin{tabular}{lccc}
\hline & \multicolumn{2}{c}{ Trier Social Stress Test $\boldsymbol{n}=\mathbf{4 5}$} \\
\cline { 2 - 4 } & $\begin{array}{l}\text { Family } \\
\text { history } \\
\text { positive }\end{array}$ & $\begin{array}{c}\text { Family } \\
\text { history } \\
\text { negative }\end{array}$ & p-value \\
\hline Sample size & 17 & 28 & \\
STAl, mean (SD) & & & NS \\
Before the TSST & $21(7.1)$ & $24(6.8)$ & NS \\
Following the TSST & $29(9.9)$ & $27(10.6)$ & \\
Response scores & $8(5.7)$ & $3(9.6)$ & $z=-2.67, p=0.007$ \\
\hline
\end{tabular}

NS, non-significant.

were negatively associated with anxiety responses in FHP subjects $(t=-2.30, p=0.024)$. To corroborate this finding, data were also analyzed in a regression analysis using cortisol AUC summary scores as the dependent measure (Figure 4). The relationship between cortisol and anxiety in this analysis was again found to be positive in the FHN subjects $(t=3.97$, $p<0.001)$ and negative in the FHP subjects, although it was marginally significant $(t=-1.93, p=0.076)$.

\section{DISCUSSION}

In this study, we employed a well-validated, laboratorybased psychological stress test to compare the stress hormone responses in social drinking individuals with and without a family history of alcohol dependence. Furthermore, we evaluated the anxiety ratings between the family history groups. There are several important findings that have emerged from this work. First, cortisol levels following the stressor were significantly higher in Caucasians with a positive family history for alcoholism than in Caucasians with a negative family history for alcoholism. Second, although we did not identify a family history effect
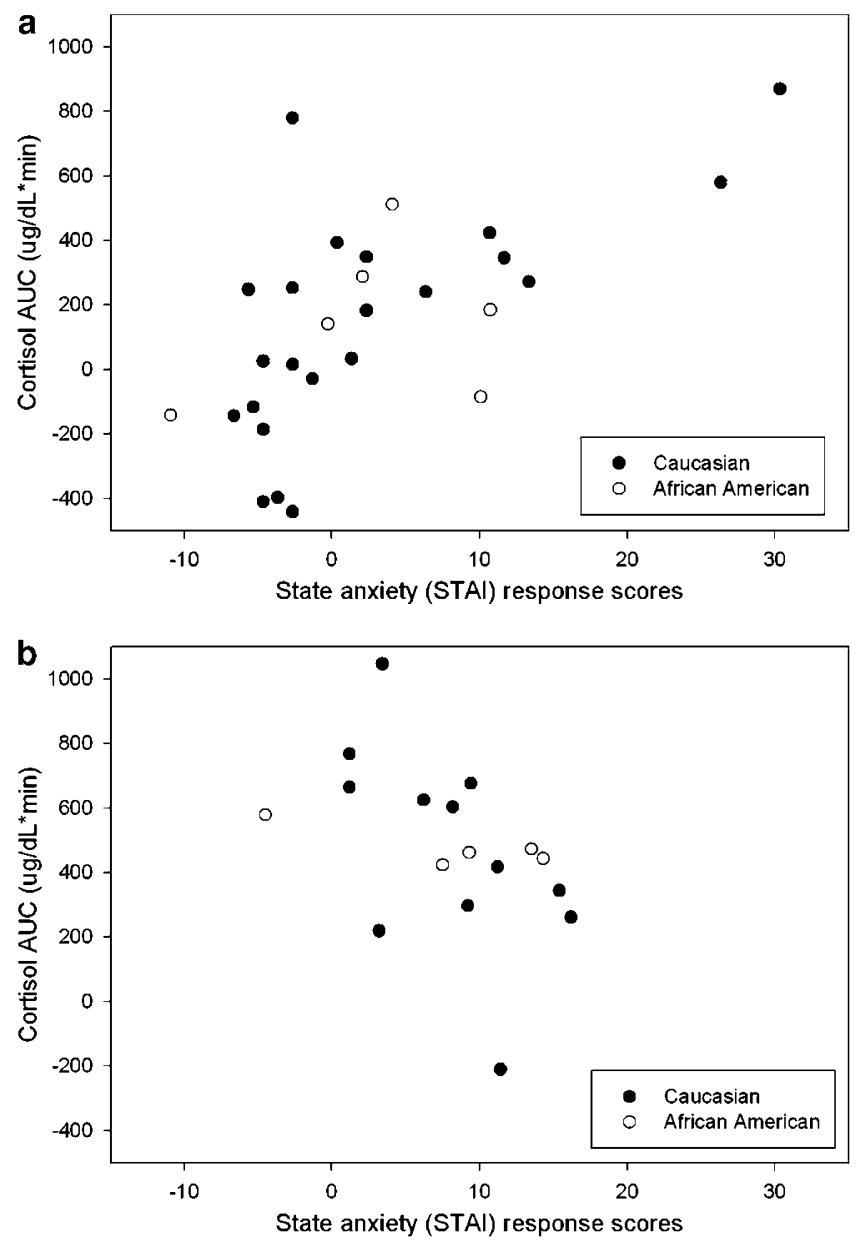

Figure 4 Relationship between cortisol AUC in response to the TSST and state anxiety (STAl) response scores. Figures were constructed from the adjusted values. (a) FHN. Number of subjects in each subgroup: Caucasian =22, African American=6. (b) FHP. Number of subjects in each subgroup: Caucasian $=12$, African American $=5$.

on ACTH responses to the TSST, ACTH responses in FHN subjects were dependent on baseline hormone levels. This was not observed in FHP subjects. Third, there were no differences in prolactin secretion in response to the TSST in FHP subjects compared to individuals without a family history of alcohol dependence. Fourth, anxiety response scores to the TSST were higher in FHP compared to FHN subjects. In addition, anxiety response scores were positively correlated with cortisol response levels in FHN subjects, but were negatively correlated in FHP subjects. It has been shown that mood and personality dimensions can influence cortisol responses to stress (Oswald et al, 2006). However, our subjects were healthy individuals without DSM-IV axis I diagnoses who did not differ on a comprehensive assessment of mood, anxiety, or personality dimensions at baseline. Therefore, the cortisol findings are unlikely the result of differences in psychological symptomology or personality dimensions between the family history of alcoholism groups. In addition to mood and personality, another potential confounder of HPA-axis studies is tobacco and alcohol use. Given that cigarette smoking and heavy alcohol use are known to alter the activity of the HPA axis (Adinoff et al, 1998; del Arbol et al, 
2000; Mendelson et al, 2005), we decided to employ stringent exclusion criteria for tobacco and alcohol. Therefore, our findings demonstrate that independent of significant alcohol and tobacco exposure, family history influences hormonal responses to stress.

Our findings showing that cortisol responses were higher in Caucasian FHP subjects than in Caucasian FHN subjects are consistent with theories that greater reactivity to stress is associated with greater risks for alcoholism (Higley et al, 1991; Fahlke et al, 2000). To the best of our knowledge, only two studies have specifically examined the relationship of HPA axis hormonal responses to psychological stress with family history of alcoholism (Dai et al, 2002; Zimmermann et al, 2004). Our observations are in agreement with those of Zimmermann et al (2004), who demonstrated that FHP Caucasian males had higher cortisol and ACTH responses to the TSST compared to FHN Caucasian males. However, Dai et al (2002) reported different findings, with lower stress-induced increase in ACTH in FHP than FHN, and no differences in cortisol response as a function of family history of alcoholism. Differences in family history classification, characteristics of the stressor, and racial composition might explain the discrepancy between studies.

Previous studies have demonstrated differences in HPAaxis activity following physiological stimulation between Caucasians and African Americans (Yanovski et al, 1996, 2000). These studies show that African Americans mount higher ACTH but similar cortisol responses to an exercise test or following corticotropin-releasing factor administration compared to Caucasians. However, in another study, salivary cortisol response to awakening was heightened in Caucasians with higher education compared to lower educated Caucasians and all African-American participants (Bennett et al, 2004). In our study, African Americans had minimal but significant cortisol responses to the TSST. To our knowledge, this is the first time that hormone response differences by race using the TSST have been demonstrated. We are uncertain of the significance of this finding that warrants replication. Our findings suggest that race should be taken into account when evaluating associations between family history of alcoholism and hormonal response to stress. However, the small number of African Americans in our study precludes definitive conclusions about a lack of family history effects in this subpopulation. Hence, our findings are indicative of the importance of future investigations using larger subgroups of subjects.

Our findings are consistent with previous studies that have employed pharmacological and physiological paradigms to activate the HPA axis. Specifically, stimulation of the HPA axis by administration of the opioid receptor antagonists naloxone hydrochloride and naltrexone has resulted in higher ACTH and/or cortisol response in FHP than FHN subjects (Wand et al, 1998, 1999a, b, 2001; Hernandez-Avila et al, 2002; King et al, 2003). However, our group has also shown no differences in cortisol response between FHP and FHN subjects following direct adrenal stimulation with the ACTH analog cosyntropin (Wand et al, $1999 \mathrm{~b}$ ) or in the $24 \mathrm{~h}$ cortisol circadian profile (Wand et al, $1999 b)$, suggesting that specific stimuli are required to differentially activate the HPA axis as a function of family history of alcoholism.
There is prior evidence showing prolactin elevation in response to psychological stress in healthy subjects (Kirschbaum et al, 1993; Sobrinho et al, 2003). To our knowledge, the present study is the first to examine prolactin response to a psychological stressor as a function of family history of alcoholism. Prolactin is a stress hormone, but is regulated by neural circuitry distinct from the neurotransmitter systems governing activation of the HPA axis (Van de Kar and Blair, 1999). Including prolactin responses in this study allowed us to determine whether the family history effect on cortisol would generalize to another stress hormone system. However, we observed no differences in prolactin responses to the TSST in FHP subjects compared with FHN subjects. We posit that the specific neurotransmitter systems regulating stress-induced prolactin release may not differ as a function of family history of alcoholism. Taken together with our other findings, these data suggest that differences in HPA axis dynamics as a function of family history of alcoholism do not extrapolate to all conditions and stress hormone systems.

Although we did not identify a family history effect on ACTH responses to the TSST, an interaction between baseline ACTH and family history was detected. The interaction demonstrated that baseline ACTH levels correlated with the magnitude of the ACTH response in FHN but not FHP subjects. It is known that endocrine stress reactivity could depend on baseline hormone levels. Indeed, Kudielka et al (2004) reported that pre-stress ACTH levels showed positive correlations with subsequent ACTH response levels in healthy individuals. Therefore, it is possible that lack of correlation between baseline ACTH and ACTH responses to the TSST in FHP subjects also signifies altered regulation of the HPA axis in this group. This is supported by our observation that FHP and FHN subjects have similar ACTH responses to the stress test but different cortisol responses, suggesting that the FHP subjects have some degree of glucocorticoid negative feedback dysregulation and/or enhanced adrenal sensitivity to endogenous ACTH (eg, adrenal hypertrophy). However, further studies are needed to test this hypothesis.

Information on the subjective feelings of anxiety in subjects under stress allows for a more comprehensive examination of the stress response. In our study, anxiety response scores to the TSST were higher in FHP compared to FHN subjects after adjusting for gender and race. These findings are consistent with the hypothesis that higher levels of anxiety are associated with greater risks for alcoholism (Merikangas et al, 1998). In agreement with our study, Zimmermann et al (2004) observed that the perceived stress rating following the stressor was higher in FHP compared to FHN subjects. In addition, we observed that anxiety response scores were positively correlated with cortisol responses in FHN subjects but were negatively correlated in FHP subjects. Thus, the perception of stress paralleled the hormonal responses to stress in FHN subjects, but not in FHP subjects. In concordance with our study, Zimmermann et al (2004) made a similar observation and suggested that the physiological response to a stressor and the subjective perception of stress might be dissociated in offspring of alcoholics. Similarly, discrepancies between selfreported emotional arousal and cortisol response following a psychosocial stress have been observed in an anorexia nervosa group (Zonnevylle-Bender et al, 2005). 
The present study has several weaknesses. It would have been ideal to have a larger sample size to make a more definitive statement regarding cortisol responses as a function of family history in African Americans. Based on our study, no conclusions should be made on the influence of race on the relationship between family history of alcoholism and hormonal stress responses. In our study, multigenerational alcoholism was not required to define subjects as FHP. Therefore, in some FHP subjects, the genetic factors leading to alcoholism may have been modest or weak, potentially minimizing stress hormone differences between groups. Moreover, given that cigarette smoking and heavy alcohol use modify the activity of the HPA axis (Adinoff et al, 1998; del Arbol et al, 2000; Mendelson et al, 2005), we employed stringent exclusion criteria for tobacco and alcohol exposure, so as to not confound the cortisol responses by these environmental factors. However, this came at a cost of employing a group of FHP subjects who may not have the same degree of susceptibility for alcohol use disorders as a group of FHP subjects who are already heavy drinkers and smokers. Despite using a 'healthier' group of FHP subjects, family history of alcoholism still predicted cortisol responses to the TSST. Our study captured HPA axis responses only on a single occasion. Thus, it is plausible that a design that captured the effects of chronic stress may have resulted in different findings. Lastly, one needs to be cautious about extrapolating findings from a laboratory-based stressor to real life situations.

In summary, cortisol responses were significantly higher in Caucasians with a positive family history for alcoholism compared to Caucasians with a negative family history for alcoholism. In addition, the findings suggest that the association between the HPA axis hormonal response and the subjective perception of stress might be deranged in offspring of alcoholics. Further studies are required to assess the mechanisms involved in these processes.

\section{ACKNOWLEDGEMENTS}

This work was supported by NIH Grants AA 10158 (GSW), AA 12303 (GSW), and AA 12837 (MEM), a gift from the Kenneth A Lattman Foundation (GSW), and Grant M01 RR00052 (GCRC). We thank Lisa Yanek (MPH) for her technical advice in this manuscript.

\section{REFERENCES}

Adinoff B, Iranmanesh A, Veldhuis J, Fisher L (1998). Disturbances of the stress response: the role of the HPA axis during alcohol withdrawal and abstinence. Alcohol Health Res World 22: 67-72.

Beck AT, Steer RA, Brown G (1996). Beck Depression Inventory-II Manual. San Antonio, TX.

Begleiter H, Porjesz B, Bihari B, Kissin B (1984). Event-related brain potentials in boys at risk for alcoholism. Science 225: 1493-1496.

Bennett GG, Merritt MM, Wolin KY (2004). Ethnicity, education, and the cortisol response to awakening: a preliminary investigation. Ethn Health 9: 337-347.

Blevins Jr LS, Dobs AS, Wand GS (1994). Naloxone-induced activation of the hypothalamic-pituitary-adrenal axis in suspected central adrenal insufficiency. Am J Med Sci 308: 167-170.

Brewer DD, Catalano RF, Haggerty K, Gainey RR, Fleming CB (1998). A meta-analysis of predictors of continued drug use during and after treatment for opiate addiction. Addiction 93: 73-92.

Brown SA, Vik PW, McQuaid JR, Patterson TL, Irwin MR, Grant I (1990). Severity of psychosocial stress and outcome of alcoholism treatment. J Abnorm Psychol 99: 344-348.

Bucholz KK, Cadoret R, Cloninger CR, Dinwiddie SH, Hesselbrock VM, Nurnberger Jr JI et al (1994). A new, semi-structured psychiatric interview for use in genetic linkage studies: a report on the reliability of the SSAGA. J Stud Alcohol 55: 149-158.

Cloninger CR, Bohman M, Sigvardsson S (1981). Inheritance of alcohol abuse. Cross-fostering analysis of adopted men. Arch Gen Psychiatry 38: 861-868.

Cohen S, Kamarck T, Mermelstein R (1983). A global measure of perceived stress. J Health Soc Behav 24: 385-396.

Cole G, Tucker L, Friedman GM (1990). Relationships among measures of alcohol drinking behavior, life-events and perceived stress. Psychol Rep 67: 587-591.

Cook CJ (2002). Glucocorticoid feedback increases the sensitivity of the limbic system to stress. Physiol Behav 75: 455-464.

Costa Jr PT, McCrae RR (1992a). Normal personality assessment in clinical practice: the NEO Personality Inventory. Psychol Assess 4: 5-13.

Costa Jr PT, McCrae RR (1992b). Revised NEO Personality Inventory: Professional Manual. Odessa, FL.

Cotton NS (1979). The familial incidence of alcoholism: a review. J Stud Alcohol 40: 89-116.

Dai X, Thavundayil J, Gianoulakis C (2002). Response of the hypothalamic-pituitary-adrenal axis to stress in the absence and presence of ethanol in subjects at high and low risk of alcoholism. Neuropsychopharmacology 27: 442-452.

Dawson DA, Grant BF, Ruan WJ (2005). The association between stress and drinking: modifying effects of gender and vulnerability. Alcohol Alcohol 40: 453-460.

del Arbol JL, Munoz JR, Ojeda L, Cascales AL, Irles JR, Miranda MT et al (2000). Plasma concentrations of beta-endorphin in smokers who consume different numbers of cigarettes per day. Pharmacol Biochem Behav 67: 25-28.

Derogatis LR, Melisaratos N (1983). The brief symptom inventory: an introductory report. Psychol Med 13: 595-605.

Fahlke C, Lorenz JG, Long J, Champoux M, Suomi SJ, Higley JD (2000). Rearing experiences and stress-induced plasma cortisol as early risk factors for excessive alcohol consumption in nonhuman primates. Alcohol Clin Exp Res 24: 644-650.

Federenko IS, Nagamine M, Hellhammer DH, Wadhwa PD, Wust S (2004). The heritability of hypothalamus pituitary adrenal axis responses to psychosocial stress is context dependent. J Clin Endocrinol Metab 89: 6244-6250.

Gold PW, Chrousos GP (2002). Organization of the stress system and its dysregulation in melancholic and atypical depression: high vs low CRH/NE states. Mol Psychiatry 7: 254-275.

Goodwin DW (1984). Studies of familial alcoholism: a review. J Clin Psychiatry 45: 14-17.

Goodwin DW, Schulsinger F, Moller N, Hermansen L, Winokur G, Guze SB (1974). Drinking problems in adopted and nonadopted sons of alcoholics. Arch Gen Psychiatry 31: 164-169.

Heath AC, Bucholz KK, Madden PA, Dinwiddie SH, Slutske WS, Bierut LJ et al (1997). Genetic and environmental contributions to alcohol dependence risk in a national twin sample: consistency of findings in women and men. Psychol Med 27: 1381-1396.

Hernandez-Avila CA, Oncken C, Van Kirk J, Wand G, Kranzler HR (2002). Adrenocorticotropin and cortisol responses to a naloxone challenge and risk of alcoholism. Biol Psychiatry 51: 652-658.

Higley JD, Hasert MF, Suomi SJ, Linnoila M (1991). Nonhuman primate model of alcohol abuse: effects of early experience, personality, and stress on alcohol consumption. Proc Natl Acad Sci USA 88: 7261-7265. 
Jose BS, van Oers HA, van de Mheen HD, Garretsen HF, Mackenbach JP (2000). Stressors and alcohol consumption. Alcohol Alcohol 35: 307-312.

Karlsgodt KH, Lukas SE, Elman I (2003). Psychosocial stress and the duration of cocaine use in non-treatment seeking individuals with cocaine dependence. Am J Drug Alcohol Abuse 29: 539-551.

King AC, Bernardy NC, Hauner K (2003). Stressful events, personality, and mood disturbance: gender differences in alcoholics and problem drinkers. Addict Behav 28: 171-187.

Kirschbaum C, Pirke KM, Hellhammer DH (1993). The 'Trier Social Stress Test' - a tool for investigating psychobiological stress responses in a laboratory setting. Neuropsychobiology 28: $76-81$.

Koob GF (2003). Alcoholism: allostasis and beyond. Alcohol Clin Exp Res 27: 232-243.

Kudielka BM, Schommer NC, Hellhammer DH, Kirschbaum C (2004). Acute HPA axis responses, heart rate, and mood changes to psychosocial stress (TSST) in humans at different times of day. Psychoneuroendocrinology 29: 983-992.

Lazarus RS, Folkman S (1989). Manual Hassles And Uplifts Scales. Mind Garden: Redwood City, CA.

Marinelli M, Piazza PV (2002). Interaction between glucocorticoid hormones, stress and psychostimulant drugs. Eur J Neurosci 16: 387-394.

McBride WJ (2002). Central nucleus of the amygdala and the effects of alcohol and alcohol-drinking behavior in rodents. Pharmacol Biochem Behav 71: 509-515.

McEwen BS (1998). Protective and damaging effects of stress mediators. N Engl J Med 338: 171-179.

Mendelson JH, Sholar MB, Goletiani N, Siegel AJ, Mello NK (2005). Effects of low- and high-nicotine cigarette smoking on mood states and the HPA axis in men. Neuropsychopharmacology 30: 1751-1763.

Merikangas KR, Mehta RL, Molnar BE, Walters EE, Swendsen JD, Aguilar-Gaziola S et al (1998). Comorbidity of substance use disorders with mood and anxiety disorders: results of the International Consortium in Psychiatric Epidemiology. Addict Behav 23: 893-907.

Miller DB, O'Callaghan JP (2002). Neuroendocrine aspects of the response to stress. Metabolism 51: 5-10.

Oswald L, Zandi P, Nestadt G, Potash J, Kalaydijian A, Wand G (2006). Relationship between cortisol responses to stress and personality. Neuropsychopharmacology, 11 January [Epub ahead of print].

Pandey SC (2003). Anxiety and alcohol abuse disorders: a common role for CREB and its target, the neuropeptide $\mathrm{Y}$ gene. Trends Pharmacol Sci 24: 456-460.

Prescott CA, Kendler KS (1999). Genetic and environmental contributions to alcohol abuse and dependence in a population-based sample of male twins. Am J Psychiatry 156: 34-40.

Pruessner JC, Kirschbaum C, Meinlschmid G, Hellhammer DH (2003). Two formulas for computation of the area under the curve represent measures of total hormone concentration versus time-dependent change. Psychoneuroendocrinology 28: 916-931.

Rice JP, Reich T, Bucholz KK, Neuman RJ, Fishman R, Rochberg N et al (1995). Comparison of direct interview and family history diagnoses of alcohol dependence. Alcohol Clin Exp Res 19: $1018-1023$.

Robison CL, Meyerhoff JL, Saviolakis GA, Chen WK, Rice KC, Lumley LA (2004). A CRH1 antagonist into the amygdala of mice prevents defeat-induced defensive behavior. Ann NY Acad Sci 1032: $324-327$.

Sapolsky RM (2000). Glucocorticoids and hippocampal atrophy in neuropsychiatric disorders. Arch Gen Psychiatry 57: 925-935.

Sarason IG, Johnson JH, Siegel JM (1978). Assessing the impact of life changes: development of the Life Experiences Survey. J Consult Clin Psychol 46: 932-946.
Schuckit MA, Gold E, Risch C (1987). Plasma cortisol levels following ethanol in sons of alcoholics and controls. Arch Gen Psychiatry 44: 942-945.

Schuckit MA, Smith TL (1996). An 8-year follow-up of 450 sons of alcoholic and control subjects. Arch Gen Psychiatry 53: $202-210$

Sherwood Brown E, Varghese FP, McEwen BS (2004). Association of depression with medical illness: does cortisol play a role? Biol Psychiatry 55: 1-9.

Sobrinho LG, Simoes M, Barbosa L, Raposo JF, Pratas S, Fernandes PL et al (2003). Cortisol, prolactin, growth hormone and neurovegetative responses to emotions elicited during an hypnoidal state. Psychoneuroendocrinology 28: 1-17.

Spielberger CD (1983). State-Trait Anxiety Inventory (STAI) Manual. Redwood City, CA.

Sussman S, Dent CW (2000). One-year prospective prediction of drug use from stress-related variables. Subst Use Misuse 35: 717-735.

Tsigos C, Chrousos GP (2002). Hypothalamic-pituitary-adrenal axis, neuroendocrine factors and stress. J Psychosom Res 53: 865-871.

Uhart M, McCaul ME, Oswald LM, Choi L, Wand GS (2004). GABRA6 gene polymorphism and an attenuated stress response. Mol Psychiatry 9: 998-1006.

Van de Kar LD, Blair ML (1999). Forebrain pathways mediating stress-induced hormone secretion. Front Neuroendocrinol 20: $1-48$.

Waltman C, McCaul ME, Wand GS (1994). Adrenocorticotropin responses following administration of ethanol and ovine corticotropin-releasing hormone in the sons of alcoholics and control subjects. Alcohol Clin Exp Res 18: 826-830.

Wand G, McCaul ME, Gotjen D, Reynolds J, Lee S (2001). Confirmation that offspring from families with alcohol-dependent individuals have greater hypothalamic-pituitary-adrenal axis activation induced by naloxone compared with offspring without a family history of alcohol dependence. Alcohol Clin Exp Res 25: 1134-1139.

Wand GS, Mangold D, Ali M (1999a). Adrenocorticotropin responses to naloxone in sons of alcohol-dependent men. J Clin Endocrinol Metab 84: 64-68.

Wand GS, Mangold D, Ali M, Giggey P (1999b). Adrenocortical responses and family history of alcoholism. Alcohol Clin Exp Res 23: $1185-1190$.

Wand GS, Mangold D, El Deiry S, McCaul ME, Hoover D (1998). Family history of alcoholism and hypothalamic opioidergic activity. Arch Gen Psychiatry 55: 1114-1119.

Wand GS, Waltman C, Martin CS, McCaul ME, Levine MA, Wolfgang D (1994). Differential expression of guanosine triphosphate binding proteins in men at high and low risk for the future development of alcoholism. J Clin Invest 94: 1004-1011.

Yanovski JA, Yanovski SZ, Boyle AJ, Gold PW, Sovik KN, Sebring NG et al (2000). Hypothalamic-pituitary-adrenal axis activity during exercise in African American and Caucasian women. J Clin Endocrinol Metab 85: 2660-2663.

Yanovski JA, Yanovski SZ, Friedman TC, Loh YP, Jayasvasti V, Cutler Jr GB et al (1996). Etiology of the differences in corticotropin-releasing hormone-induced adrenocorticotropin secretion of black and white women. J Clin Endocrinol Metab 81: 3307-3311.

Zimmermann U, Spring K, Kunz-Ebrecht SR, Uhr M, Wittchen HU, Holsboer F (2004). Effect of ethanol on hypothalamicpituitary-adrenal system response to psychosocial stress in sons of alcohol-dependent fathers. Neuropsychopharmacology 29: $1156-1165$.

Zonnevylle-Bender MJ, van Goozen SH, Cohen-Kettenis PT, Jansen LM, van Elburg A, Engeland H (2005). Adolescent anorexia nervosa patients have a discrepancy between neurophysiological responses and self-reported emotional arousal to psychosocial stress. Psychiatry Res 135: 45-52. 